\title{
Maternal Factors in Neonatal Hypocalcaemia: A Study in Three Ethnic Groups*
}

\author{
PATSY J. M. WATNEY, G. W. CHANCE， P. SCOTT, JOAN M. THOMPSON
}

British Medical fournal, 1971, 2, 432-436

\section{Summary}

To assess the significance of various maternal and neonatal factors in the aetiology of neonatal tetany we have investigated the serum calcium, phosphorus, magnesium, and heatlabile alkaline phosphatase of 250 mothers from three ethnic groups at several stages of pregnancy and the serum calcium, phosphorus, and magnesium of many of their infants. Subclinical hypocalcaemia was found to be much commoner in full-term infants on the sixth day of life than is generally appreciated, especially during the winter months and in babies of Asian parents. It is considered that this is a result of high phosphorus loads in artificial milks and is also influenced by maternal vitamin $D$ and possibly calcium intake during pregnancy. The importance of ensuring that Asian women take adequate vitamin $D$ supplements during pregnancy is stressed.

\section{Introduction}

In recent years, in common with many other maternity departments, we have noted an apparent increase in the frequency of hypocalcaemic convulsions in the newborn period. Most authors have attributed this increase to the practice of early feeding with large volumes of cow's milk preparations (Baum et al., 1968), though Southgate et al. (1969) also stressed the importance of the quantity of calcium lost in the stools as salts of fatty acids. Fanconi and Prader (1967) suggested that most of the reported cases were instances of mild transient hypoparathyroidism aggravated by the above factors. However, features such as a high incidence of symptomatic hypocalcaemia in infants of Asian mothers, a low incidence in infants of West Indian mothers, occasional instances in entirely breast-fed infants, and a pronounced seasonal variation in frequency suggested to us that maternal factors might also be of importance. We have therefore studied a group of mothers and their babies to assess this possibility.

\section{Patients and Methods}

Asian, West Indian, and Caucasian patients attending the Sorrento Maternity Hospital antenatal clinic were included in the study. They were admitted to the study in sequence over a period of 12 months until there were at least 40 patients in

*This work formed a part of a dissertation submitted for the degree of M.D. of Cambridge University by one of us (P.J.M.W.).

\section{Sorrento Maternity Hospital, Birmingham 13}

PATSY J. M. WATNEY, M.B., M.R.C.O.G., Locum Consultant Obstetrician (At present: Senior Registrar, Birmingham Maternity Hospital, Birmingham 15)

G. W. CHANCE, M.R.C.P., D.C.H., Honorary Consultant Paediatrician (At present: Associate Professor, Department of Neonatology, the Hospital for Sick Children, Toronto 101, Ontario, Canada)

Selly Oak Hospital, Birmingham 29

P. SCOTT, M.R.C.PATH., F.R.I.C., Biochemist

Birmingham Regional Hospital Board, Birmingham 15

JOAN M. THOMPSON, B.Sc., Statistician each of the three racial groups. At their first visit all the patients were asked to take 1 tablet a day containing vitamin A $4,000 \mathrm{IU}$, vitamin D $400 \mathrm{IU}$, calcium phosphate $250 \mathrm{mg}$, and potassium iodide $0.13 \mathrm{mg}$ and to drink at least 1 pint $(570 \mathrm{ml})$ of milk daily. Towards the end of pregnancy they were asked whether or not they had done so.

Blood samples were taken at the 29th and 36th weeks of pregnancy, from the umbilical cord at delivery, and from the infants on the sixth day after birth. In as many instances as possible blood samples were also taken at first attendancethat is, between the 10th and 20th weeks of pregnancy (mean 15 weeks) in each race-and at the postnatal visit six weeks after delivery. In a few, blood was taken from the mother at the time of delivery. Maternal samples were collected without venostasis with plastic syringes and transferred to a plastic container. Infants' samples were obtained by a heel-prick before the 10 a.m. feed on the sixth day and collected in Caraway heparinized tubes. In all instances the serum (plasma in the infants) was separated within four hours of collection. Cord blood samples were allowed to clot, and the serum was separated usually within 12 hours.

Calcium was estimated with the AutoAnalyzer. Technicon methodology N-3a was used, except that the smaller amounts of the neonatal samples were analysed using a $1: 1$ sample wash cam, instead of $2: 1$ cam used for the adults. The two means of a series of specimens analysed by the two variants were not significantly different. Quality control data showed a maximum shift of $0.1 \mathrm{mg} / 100 \mathrm{ml}$ due to analytical variation between the absolute levels of calcium reported in each of the four three-month periods of the "seasonal variation" experiment.

Phosphate was estimated with AutoAnalyzer (Technicon methodology N-4b). Magnesium was analysed by a continuous-flow automated micromethod (Scott and Warner, 1968) with Technicon modules plus a Locarte fluorometer and based on the manual method of Schachter (1959). Alkaline phosphatase was estimated with the AutoAnalyzer (Technicon methodology $\mathrm{N}-6 \mathrm{a}$ ). The use of untreated serum gave total alkaline phosphatase, while heat-stable alkaline phosphatase was obtained by using serum which had been previously heated at $56^{\circ} \mathrm{C}$ for 30 minutes in a water bath to destroy the heat-labile, non-placental fraction (Neale et al., 1965). Serum heat-labile alkaline phosphatase was then calculated.

\section{Results in Mothers}

The mean values for serum calcium, phosphorus, magnesium, and heat-labile alkaline phosphatase in mothers of the three ethnic groups at first attendance, 29 and 36 weeks' gestation, and postnatal visit at six weeks are shown in Table I. The mean serum calcium was lower in the Asian mothers than in the Caucasian and West Indian mothers throughout pregnancy and postnatally, the difference being highly significant at booking and 36 weeks' gestation $(P<0.01$. At 29 and 36 weeks' gestation mean values for serum phosphorus were higher in West Indians than in Caucasians and Asians, and mean alkaline phosphatase* values were higher in the Asian mothers than in the other two groups $(P<0.01$ at 36 weeks). At the postnatal visit the mean serum phosphorus and alkaline phosphatase

*All references to "alkaline phosphate" throughout refer to the heat-labile fraction. 
TABle I-Mean Values of Serum Calcium, Phosphorus, Magnesium, and Heat-labile Alkaline Phosphatase in Asian, Caucasian, and West Indian Mothers at First Antenatal Visit (10 to 20 Weeks), 29 and 36 Weeks' Gestation, and Sixth Week Postnatally, and in their Infants (Cord and Sixth-day Samples)

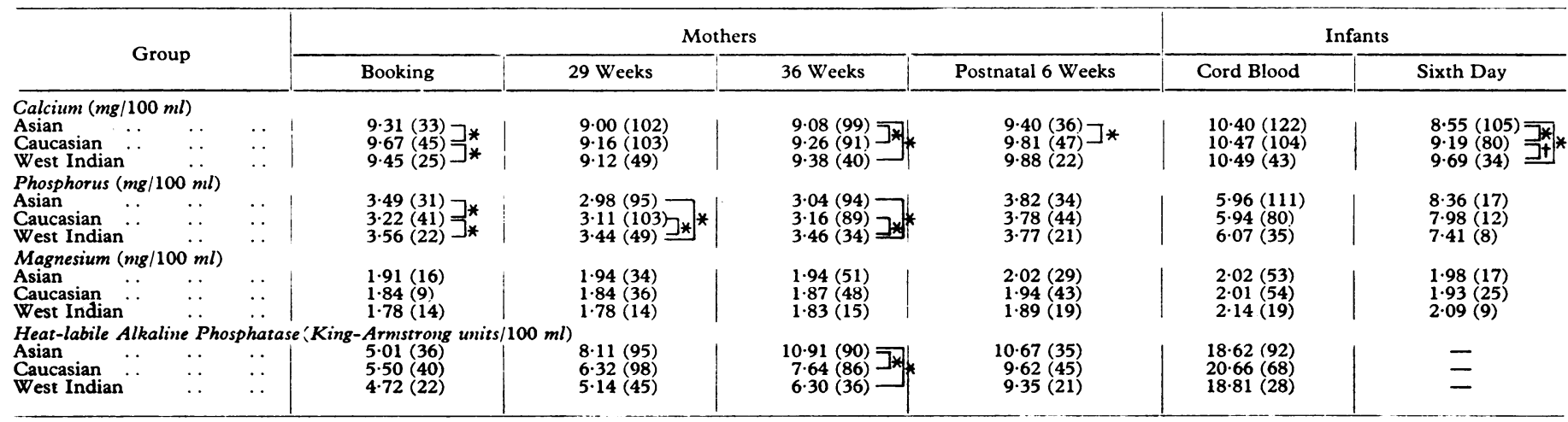

Figures in parentheses $=$ number of patients examined.

$\stackrel{*}{+} 0.01 .<0 . \dot{P}<0.05$.

had risen to similar levels in all three groups. Differences in the mean serum magnesium values for the three groups of mothers did not reach statistical significance but they were higher at each sampling in the Asian mothers, the opposite of the trend for serum calcium.

\section{Results in Infants}

CORD BLOOD RESULTS

Only minor and non-significant differences were noted in the mean serum calcium, phosphorus, alkaline phosphatase, and magnesium in the mixed arteriovenous cord blood of the infants of these mothers (see Table I). However, all values except magnesium were considerably higher than had been found in their mothers at 36 weeks. Serum obtained from a small group of mothers at parturition and from their infants showed that mean maternal calcium, phosphorous, and alkaline phosphatase values were only slightly higher than they had been at 36 weeks and were considerably lower than in their infants' cord blood.

\section{SIXTH-DAY SERUM CALCIUM}

Despite only minor differences in serum calcium in the cord blood, highly significant difierences in the means for infants of each racial group were found by the sixth day of life (see Table I). The mean in infants of Asian mothers was $8.55 \mathrm{mg} /$ $100 \mathrm{ml}$ compared with $9.19 \mathrm{mg} / 100 \mathrm{ml}$ in the Europeans and $9.69 \mathrm{mg} / 100 \mathrm{ml}$ in the West Indians. The serum calcium was less than $8 \mathrm{mg} / 100 \mathrm{ml}$ on the sixth day in 32 out of 96 Asian

infants $(33 \%)$, in 14 out of 74 Caucasian infants (19\%), and in 2 out of 29 West Indian infants (7\%). The quantity of serum obtained from heel-prick samples restricted statistical analysis to serum calcium. Nevertheless, the mean serum phosphorus in babies of Asian mothers $(8.36 \mathrm{mg} / 100 \mathrm{ml}$ ) was considerably higher than that found in the West Indians $(7.41 \mathrm{mg} / 100 \mathrm{ml})$.

\section{Relationship to Maternal and Cord Blood Results}

Values for Asian and for Caucasian mothers were each separated into two groups according to whether their infants' sixth-day serum calcium was greater or less than $8 \mathrm{mg} / 100 \mathrm{ml}$ and the means were calculated for calcium, phosphorus, and alkaline phosphatase (see Table II). No difference was found between the maternal serum calcium in these two groups but in Asian mothers the serum inorganic phosphorus was significantly lower and alkaline phosphatase significantly higher at 29 and 36 weeks gestation in those whose infants' serum calcium was less than $8 \mathrm{mg} / 100 \mathrm{ml}$ on the sixth day. The findings were less striking in Caucasian mothers compared in this way though the serum inorganic phosphorus at 29 and 36 weeks' gestation followed a similar trend. In the infants the mean cord blood inorganic phosphorus showed a similar but nonsignificant trend in both races. Cord blood alkaline phosphatase was significantly higher in the low calcium group of Asian infants. This latter finding was not repeated in the cord blood of the Caucasian infants, in whom the mean serum alkaline phosphatase of the low calcium group $(12.72 \mathrm{U} / 100 \mathrm{ml})$ was considerably lower than in their Asian counterparts (21.97 $\mathrm{U} / 100 \mathrm{ml}$ ). The high mean cord blood alkaline phosphatase

TABLE II-Relation between Mean Infants' Serum Calcium on the Sixth Day and Mean Serum Calcium, Inorganic Phosphorus, and Heat-labile Alkaline Phosphatase in Mothers at 29 and 36 Weeks Gestation, Six Weeks Postnatally, and in Infants Cord Blood. Significance of Differences between Races is Not Shown Here

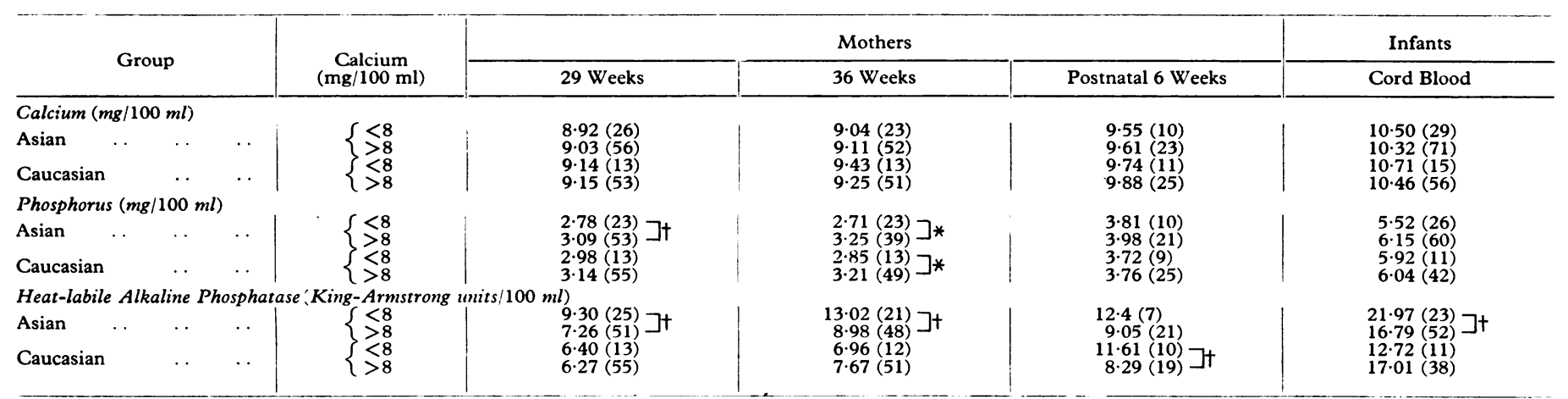

Figures in parentheses $=$ number of patients examined.

$\stackrel{* P}{+0.01<P} \mathbf{P}<0.05$

The column headed "Calcium" refers to infants on the sixth day. 
in the normocalcaemic Caucasian infants $(17.01 \mathrm{U} / 100 \mathrm{ml})$ was influenced by findings of $61 \cdot 0,42 \cdot 6$, and $35 \cdot 1 \mathrm{U} / 100 \mathrm{ml}$ in three apparently normal patients.

A significant correlation was found between a high maternal alkaline phosphatase at 36 weeks' gestation in Asian mothers and a low serum calcium on the sixth day in their infants $(P<0.01)$; this was not found in Caucasians.

\section{Effect of Maternal Diet and Infant Feeding Methods}

Detailed dietary histories were obtained from 10 patients in each group and analysed for calcium, phosphorus, phytic acid, and vitamin-D content with the use of the tables of Widdowson and McCance (1960) and Wohl and Goodhart (1968). The results (Table III) show that calcium intake was particularly deficient in the Asian mothers. Their diets also contained the highest quantity of phytic acid, so that the ratio of calcium to

TABLE III-Daily Maternal Dietary Calcium, Phosphorus, Phytic Acid, and Vitamin D. Means of Observations from 10 Patients of Each Group Questioned in Late Pregnancy

\begin{tabular}{|c|c|c|c|c|c|c|}
\hline Group & $\begin{array}{l}\text { Calcium } \\
\text { (mg/day) }\end{array}$ & $\begin{array}{c}\text { Phosphorus } \\
\text { (mg/day) }\end{array}$ & $\begin{array}{l}\text { Phytic } \\
\text { Acid } \\
\text { (mg/day) }\end{array}$ & $\begin{array}{c}\text { Calcium/ } \\
\text { Phosphorus }\end{array}$ & $\begin{array}{l}\text { Calcium/ } \\
\text { Phytic } \\
\text { Acid }\end{array}$ & $\begin{array}{l}\text { Vitamin D } \\
\text { (units/day) }\end{array}$ \\
\hline $\begin{array}{l}\text { Asian ... } \\
\text { Caucasian } \\
\text { West }\end{array}$ & $\begin{array}{r}649 \\
1,048\end{array}$ & $\begin{array}{r}952 \\
1,443\end{array}$ & $\begin{array}{r}131 \\
84\end{array}$ & $\begin{array}{l}1 \cdot 5: 1 \\
1 \cdot 4: 1\end{array}$ & $\begin{array}{r}4 \cdot 9: 1 \\
12 \cdot 5: 1\end{array}$ & $\begin{array}{l}110 \\
120\end{array}$ \\
\hline Indian & 773 & 1,067 & 44 & $1 \cdot 4: 1$ & $16 \cdot 8: 1$ & 113 \\
\hline
\end{tabular}

phytic acid was 5:1 in the Asian mothers compared with 17:1 in the West Indians. Only $50 \%$ of all Asian mothers took more than $250 \mathrm{ml}$ of milk daily compared with $84 \%$ of all European and $77 \%$ of all West Indian mothers. Dietary vitamin-D intake appeared not to differ in the three groups.

Only $7 \%$ of European infants were successfully breast-fed. The incidence of successful breast-feeding in Asians and West Indians was higher and permitted statistical analysis (Table IV). The mean serum calcium on the sixth day was again lower in Asian than in West Indian infants: indeed, the value in breast-fed Asian infants was $0.6 \mathrm{mg} / 100 \mathrm{ml}$ lower than that found in artificially-fed West Indian infants.

\section{Effect of Supplementary Vitamin D}

Dietary vitamin $\mathrm{D}$ was at the same low level (estimated to be 100-120 IU/day) in all three groups. Administration of supplementary vitamin $\mathrm{D}$ to one of two randomized groups was not considered justifiable. However, on questioning the mothers in late pregnancy $50 \%$ of the Asians, $77 \%$ of the West Indians, and $84 \%$ of the Caucasians said that they had taken vitamin tablets regularly (equivalent to $400 \mathrm{IU}$ of vitamin $\mathrm{D}$ daily). Strict accuracy in all replies is, of course, unlikely, but we felt that most answers were reliable enough to proceed with analysis of the biochemical results in mothers and infants (Table V). Asian mothers not taking regular vitamins differed significantly from those taking vitamins in mean serum calcium at first attendance-that is, before any had received added vitamins-and postnatally $(P<0.05)$, and in serum phosphorus and alkaline phosphatase at 36 weeks' gestation. Also, the alkaline phosphatase was higher in cord blood and the serum calcium lower on the sixth day $(P<0.01)$ in the infants of mothers not taking added vitamin $D$ in pregnancy. Numbers of European and West Indian mothers who admitted to failing to take added vitamins were too small to permit statistical comparisons but similar trends were observed. Among the infants of 48 Asian mothers who took vitamins during pregnancy only 10 had a serum calcium less than $8 \mathrm{mg} / 100 \mathrm{ml}$ on the sixth day compared with 23 out of 48 infants whose mothers did not $\left(x^{2}=7 \cdot 80, P<0.01\right)$.

TABLE IV-Mean Sixth-day Serum Calcium in Infants of the Three Groups Fed on Breast or Artificial Milk. The Difference between Breast and Artificial Feeding in Asian Infants was Also Significant $(\mathrm{P}<0.05)$

\begin{tabular}{|c|c|c|c|c|}
\hline \multirow{2}{*}{\multicolumn{3}{|c|}{ Group }} & \multicolumn{2}{|c|}{ Mean Serum Calcium $(\mathrm{mg} / 100 \mathrm{ml})$} \\
\hline & & & Breast & Artificial \\
\hline $\begin{array}{l}\text { Asian } . . \\
\text { Caucasian } \\
\text { West Indian }\end{array}$ & $\begin{array}{l}\ldots \\
\cdots\end{array}$ & $\begin{array}{l}\ldots \\
\ldots\end{array}$ & $\left.\begin{array}{l}8.93(33) \\
9.83(5) \\
9.76(17)\end{array}\right] *$ & $\left.\begin{array}{l}8 \cdot 23(63) \\
9 \cdot 18(69) \\
9.53(12)\end{array}\right] *$ \\
\hline
\end{tabular}

* $\mathrm{P}<0.01$.

\section{Seasonal Variations}

Because of the relatively low numbers it was possible to include only Asian and Caucasian patients in the statistical analysis.

TABle v-Mean Serum Calcium, Inorganic Phosphorus, and Heat-labile Alkaline Phosphatase in Asian Mothers according to Vitamin D Supplements in Pregnancy and in their Infants

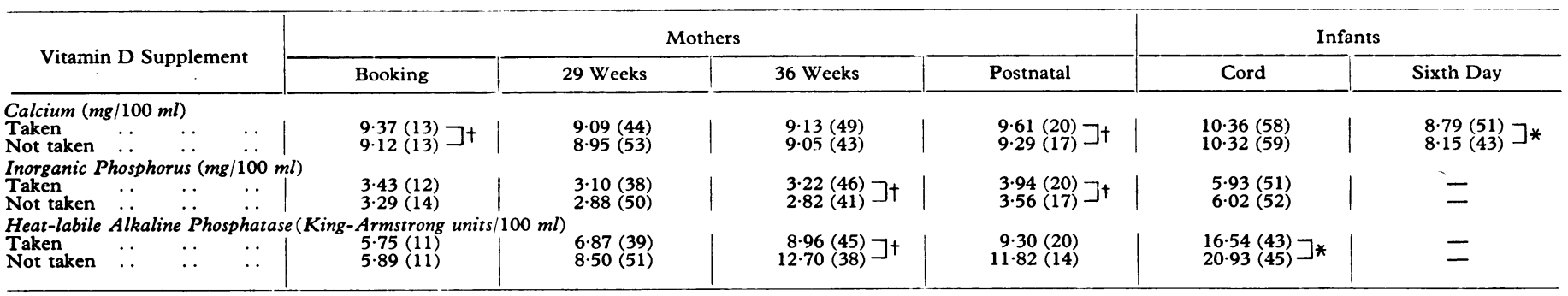

$\stackrel{*}{*} \mathbf{P}<0.01<P<0.05$.

TABLE VI-Seasonal Variation of Serum Calcium in Asian and Caucasian Mothers (29 and 36 Weeks' Gestation) and in their Infants (Sixth Day). Significance of the Difference between Races is Not Shown Here

\begin{tabular}{|c|c|c|c|c|c|c|c|}
\hline \multirow{2}{*}{\multicolumn{3}{|c|}{ Month Delivered }} & \multirow{2}{*}{\multicolumn{2}{|c|}{ Ethnic Group }} & \multicolumn{3}{|c|}{ Serum Calcium $(\mathrm{mg} / 100 \mathrm{ml})$} \\
\hline & & & & & 29 Weeks & 36 Weeks & Infant Sixth Day \\
\hline $\begin{array}{l}\text { January to March } \\
\text { April to June.. } \\
\text { July to September .. } \\
\text { October to December }\end{array}$ & $\begin{array}{l}\cdots \\
\ldots \\
\ldots\end{array}$ & $\begin{array}{l}\cdots \\
\cdots \\
\cdots\end{array}$ & $\left\{\begin{array}{l}\text { Asian } \ldots \\
\text { Caucasian } \\
\text { Asian } \ldots \\
\text { Caucasian } \\
\text { Asian } \\
\text { Caucasian } \\
\text { Asian } \\
\text { Caucasian }\end{array}\right.$ & $\begin{array}{l}\cdots \\
\cdots \\
\cdots \\
\cdots \\
\cdots \\
\cdots\end{array}$ & $\left.\left.\begin{array}{l}8.99(19) \\
8.99(14) \\
9.15(26) \\
9.51(12) \\
8.90(10) \\
9.26(13) \\
8.94(42) \\
9.03(30)\end{array}\right]+\right]^{*}$ & $\begin{array}{l}9 \cdot 10(16) \\
9 \cdot 32(11) \\
9 \cdot 18(27) \\
9 \cdot 31(9) \\
9 \cdot 10(8) \\
9 \cdot 38(11) \\
9 \cdot 04(43) \\
9 \cdot 20(29)\end{array}$ & $\left.\begin{array}{l}7.46(17) \\
8.69(18) \\
8.68(36) \\
9 \cdot 12(9) \\
8.45(13) \\
8.97(13) \\
8.88(36) \\
9.01(39)\end{array}\right]$ \\
\hline
\end{tabular}

Figures in parentheses $=$ number of patients examined. 
At each season and each stage of pregnancy mean values of serum calcium were lower in Asians than in Caucasians (Table VI). Among Asian babies, 17 born in the period January to March had a mean serum calcium of $7.46 \mathrm{mg} / 100 \mathrm{ml}$ on the sixth day.

\section{Discussion}

The results of this study of Asian, European, and West Indian mothers and their infants show that serum calcium levels on the sixth day of life are influenced considerably by the availability of vitamin $\mathrm{D}$, and possibly calcium, to the mothers during pregnancy, as well as by the more widely recognized phosphorus and fat content of the neonates' feed. Despite similar cord blood results the three groups showed important differences in mean maternal serum calcium, inorganic phosphorus, and alkaline phosphatase at 29 and 36 weeks of pregnancy which were associated with differences in their infants' serum calcium and phosphorus values at six days. Results for West Indians indicated that these mothers experience the least disturbance of calcium metabolism from fetal demands during the third trimester and that their infants were optimally prepared for the unstable calcium homoeostasis of the newborn period. Serum calcium values below $8 \mathrm{mg} / 100 \mathrm{ml}$ were encountered in only $7 \because$ of West Indian infants. Results in Asian mothers are compatible with these women meeting fetal demands for calcium and phosphorus by mobilization of their own reserves in the presence of calcium and vitamin-D deficicncy. The fact that calcium levels less than $8 \mathrm{mg} / 100 \mathrm{ml}$ were encountered in $33 \%$ of their infants suggests that these fetal demands were not always satisfied. The Caucasian mothers were from a slightly more heterogenous socioeconomic group but in general terms the effect of pregnancy on their calcium metabolism was intermediate, and this was reflected by the 18 ".. incidence of hypocalcaemia in their babies.

We consider it unlikely that the lower calcium values in the Asian mothers were due only to inherent racial differences. Nor do we feel that the differences were caused by differences in serum proteins; albumin levels in the three groups were very similar (Watncy and Scott, 1970). More probably nutrition beforc and during pregnancy accounts for the different findings in the three groups. The diet of many Asian women in this country is grossly deficient in calcium and high in phytic acid. The dietary calcium intake of West Indian women is similar to that of Asian women but their phytic acid intake is much lower, though this may have little significance because the calcium-binding effect of phytic acid is not very great.

The calculated dietary vitamin-D intake in the three ethnic groups is similar, but as with prophylactic iron therapy (Bonner et al., 1969) a high proportion of mothers fail to take their vitamin supplements in pregnancy, and this is particularly noticeable in Asian mothers, partly because of language barriers. It appears that those Asian women who fail to take added vitamins are those who are most in need of them since their mean serum calcium was lower in early pregnancy. Absorption of dietary calcium will, of course, be restricted if vitamin-D deficiency is present. The effect on endogenous Vitamin-D formation and hence on serum calcium of observations of religious practices such as Purdah by Moslem Asians is difficult to assess but even those Asian mothers to whom this does not apply clothe themselves so completely that little sunlight penetrates to the skin, especially in winter months. On the other hand, West Indian mothers, who if anything are darker skinned but who wear European clothing and are not confined to the home, were much less affected by seasonal variation, suggesting that clothing is more important than skin pigmentation in restricting vitamin-D formation.

Other reports have shown that, among Asian immigrants in Great Britain, osteomalacia and rickets are fairly common; for example, Dunnigan et al. (1962) reported that 35 out of 74 Pakistani adults and children with bone pains had osteomalacia or late rickets, and they related these findings to dietary lack of calcium and vitamin-D and to lack of endogenous vitamin-D. Ten of our Asian mothers had some of the biochemical changes of osteomalacia though the individual results have not been shown in the tables. Only two of these patients were taking the recommended vitamin-D supplements and both of these were drinking less than half a pint $(285 \mathrm{ml})$ of milk per day. Some of these patients attended for follow-up and their calcium, phosphate, and alkaline phosphatase levels showed a gradual return to normal two to three months after delivery.

Fetal demands for calcium begin at the 16th week and by term the infant contains about $30 \mathrm{~g}$ of calcium largely acquired during the last trimester (Widdowson and Spray, 1951). Our results support the view that the trough which occurs in maternal serum calcium levels at the time when fetal demands for calcium outstrip maternal dietary intake stimulates maternal parathyroid activity with consequent mobilization of skeletal calcium and restoration of serum calcium towards normal. We feel that the significant correlation between maternal alkaline phosphatase at 36 weeks and the sixth-day hypocalcaemia in the nconate indicates that maternal vitamin-D deficiency profoundly affects the calcium metabolism of the fetus. This view is supported by the fact that vitamin-D supplementation resulted in lower alkaline phosphatase levels in pregnancy and cord blood and a lower incidence of hypocalcaemia in the neonate. High postnatal alkaline phosphatase levels suggest that the maternal parathyroid hyperplasia is slow to regress.

Fetal parathyroid suppression may be the normal intrauterine physiological state resulting from high levels of ionized calcium in fetal blood maintained thus by an active placental calcium pump mechanism (Radde, personal communication). The cord blood results in our study suggest that this placental mechanism continues to function effectively over a wide range of available maternal calcium and vitamin-D. The high cord blood alkaline phosphatase levels despite high normal values for calcium and phosphorus probably reflect intense fetal osteogenesis. In neonates with symptomatic hypocalcaemia we have observed a failure of serum calcium response to large amounts of calcium administered intravenously, while concurrent radiographs of the wrists have shown rapid calcium deposition in the epiphyses. An alternative explanation for fetal parathyroid suppression is that it is due to maternal parathyroid hormone, increased secondarily to the lowered maternal serum calcium, crossing the placental barrier. There is some evidence to support this (Ludwig, 1962; Fanconi and Prader, 1967; Bronsky et al., 1968) and it would explain why infants of mothers deprived of vitamin-D are especially prone to hypocalcaemia.

We feel that neonatal vitamin-D deficiency is an unlikely explanation for neonatal tetany though it cannot be excluded. Hypocalcaemic neonates usually show a delayed response to vitamin-D administration; indeed the initial effect may be a lowering of serum calcium. Neonatal tetany has also been shown to be due to hypomagnesaemia with or without hypocalcaemia (Davis et al., 1965). We did not encounter any instances of symptomatic hypomagnesaemia during the course of this study. There was little difference in the mean serum magnesium in hypocalcaemic infants compared with normocalcaemic infants, nor was there a significant racial difference in magnesium levels.

We conclude that, in addition to feeding of high phosphorus loads in artificial milks (Oppé and Redstone, 1968) from which calcium is only poorly absorbed (Southgate et al., 1969), the variety of neonatal hypocalcaemia which is transient but which sometimes results in convulsions late in the first and during the second week of life is also influenced by maternal vitamin-D and possibly calcium intake during pregnancy. It seems that the vitamin-D status of Asian women in this country is so carefully balanced that the omission of a small vitamin-D supplement significantly affects maternal and neonatal calcium levels. It therefore follows that in addition to encouragement of breast as opposed to artificial feeding, its prevention lies in adequate attention to antenatal diet and vitamin supplements. 
We are grateful to Dr. M. Lowry and Dr. G. Kundu for their help with the project and to Miss J. Hallum and Mr. H. Mansfield for permission to study patients under their care. We would also like to thank Sister D. Nowicka and other members of the staff of Sorrento Maternity Hospital for their help.

\section{References}

Baum, D., Cooper, L., and Davies, P. A. (1968). Lancet, 1, 598. Bonner, J, Goldberg, A., and Smith, J. A (1969). Lancet, 1, 457. Bronsky, D., Kiamko, R. T., Moncada, R., and Rosenthal, I. M. (1968) Pediatrics, 42, 606 .

Davis, J. A., Harvey, D. R., and Yu, J. S. (1965). Archives of Diseasc in Childhood, 40, 286 .
Dunnigan, M. G., Paton, J. P. J., Haase, S., McNicol, G. W., Gardner, M. D., and Smith, C. M. (1962). Scottish Medical fournal, 7, 159. Fanconi, A., and Prader, A. (1967). Helvetica Paediatrica Acta, 22, 205. Fanconi, A., and Prader, A. (1967). Helvetica Paediatrica Acta, 22, 2

Neale, F. C., Clubb, J. S., Hotchkiss, D., and Prosen, S. (1965). Fournal of Clinical Pathology, 18, 359.

Oppé, T. E., and Redstone, D. (1968). Lancet, 1, 1045.

Schachter, D. (1959). Fournal of Laboratory and Clinical Medicine, 54, 763.

Scott, P., and Warner, M. (1968). Unpublished.

Southgate, D. A. T., et al. (1969). Lancet, 1, 478.

Watney, P. J. M., and Scott, P. (1970). Unpublished observations.

Widdowson, E. M., and McCance, R. A. (1960). Chemical Composition of Foods, London, H.M.S.O.

Widdowson, E. M., and Spray, C. M. (1951). Archives of Disease in Child-

hood, 26, 205 . Discase. Philadelphia, Lean and Febiger.

\title{
Effects of Oral Contraceptives on Human Plasma Vitamin-A Levels
}

\author{
ISABEL GAL, CHRISTINE PARKINSON, IAN CRAFT
}

British Medical fournal, 1971, 2, 436-438

\begin{abstract}
Summary
Vitamin-A levels have been determined in healthy nonpregnant women and in women taking synthetic steroids to suppress ovulation. A significant increase has been found in those receiving oral contraceptives. Further work is necessary to determine whether this may affect the fetus in patients who become pregnant shortly after discontinuing oral contraception.
\end{abstract}

\section{Introduction}

Oral contraception is one of the most effective methods of birth control, but after the widespread introduction of these synthetic steroids there have been numerous reports on side effects. These have largely been concerned with clinical manifestations and derangements in metabolic functions (Spellacy and Carlson, 1966; Briggs and Staniford, 1969; Laurell et al., 1968; Briggs et al., 1970; Streiff, 1970). Nevertheless, little attention has been given to the influence of these agents on possible alterations in reproductive environment.

One such prerequisite postulated for normal reproduction to occur is that optimum levels of vitamin $A$ be present. Alterations in vitamin $A$ in animals have been shown to be associated with changes in reproductive capacity and an increased incidence of congenital malformations (Giroud, 1955). Relatively little is known about the influence of variations in vitamin-A levels on human reproduction, but initial studies have suggested an association between alterations in maternal vitamin-A levels and congenital defects (Gal et al., 1971). Steroid administration may be associated with abnormal fetal development, for an

\footnotetext{
Institute of Obstetrics and Gynaecology, Queen Charlotte's Hospital, London W.6

ISABEL GAL, M.D., Clinical Lecturer

CHRISTINE PARKINSON, L.I.BIOL., Senior Research Technician

Westminster Hospital, London S.W.1

IAN CRAFT, F.R.C.S., M.R.C.o.G., Senior Registrar
}

increased incidence of chromosome abnormalities in spontaneous abortions has been reported in women who have received oral contraceptives (Carr, 1967; Dhadial et al., 1970).

Steroid administration alters the circulating vitamin-A levels. Woollam and Millen (1960) reported that the teratogenic activity of vitamin $A$ in rats is accentuated by cortisone. These facts prompted an investigation into whether oral contraceptives have any significant influence on human vitamin-A status.

\section{Subjects and Methods}

Twenty healthy young volunteer women aged 20 to 32 years, with regular menstrual cycles, acted as controls for 22 women of the same age range who had been receiving oral contraceptive tablets for at least three months. The contraceptive tablets used included Gynovlar $(0.05 \mathrm{mg}$ ethinyloestradiol and $3 \mathrm{mg}$ norethisterone acetate); Minovlar ( $0.05 \mathrm{mg}$ ethyinloestradiol and $1 \mathrm{mg}$ norethisterone acetate); Norinyl-1 (0.05 mg mestranol and $1 \mathrm{mg}$ norethisterone); Lyndiol 2.5 (0.075 $\mathrm{mg}$ mestranol and $2.5 \mathrm{mg}$. lynestrenol); Minilyn (0.05 $\mathrm{mg}$ ethinyloestradiol and $2.5 \mathrm{mg}$ lynestrenol); Ortho-novin $(0.1 \mathrm{mg}$ mestranol and $2 \mathrm{mg}$ norethisterone); Ovulen $(0.1 \mathrm{mg}$ mestranol and $1 \mathrm{mg}$ ethynodiol diacetate); and Volidan $(0.05 \mathrm{mg}$ ethinyloestradiol and $4 \mathrm{mg}$ megestrol acetate).

To assess the influence of hormone levels on vitamin- $A$ metabolism both groups were studied on two occasions during one menstrual cycle-that is, during days 3 to 5 and during days 18 to 21 , when endogenous and exogenous hormone levels are respectively first low and then high. In the contraceptive group the first sample was therefore taken in the tablet-free interval.

Blood samples were taken after an overnight fast, at the same time each morning, into syringes covered in aluminium foil because of the light sensitivity of vitamin $A$. The samples were then centrifuged in foil-covered containers and the plasma was separated in a dark room and stored at $-20^{\circ} \mathrm{C}$. Vitamin-A and carotenoid levels were assayed by the Yudkin (1941) modification of the Kimble (1939) method.

To establish whether synthetic steroids interfere with these analyses, norethisterone acetate and ethinyloestradiol were added to plasma in concentrations equivalent to the highest levels found in the plasma of those receiving these particular preparations. The vitamin $\mathrm{A}$ was then assayed and the result 